\title{
Homocysteine and oxidative stress in acute stroke*
}

\author{
Laura Nanetti $^{1 \# \dagger}$, Arianna Vignini ${ }^{1 \#}$, Francesca Raffaelli ${ }^{1}$, Alessia Giulietti ${ }^{1}$, Marco Bartolini ${ }^{2}$, \\ Cecilia Perozzi $^{2}$, Mauro Silvestrini ${ }^{2}$, Leandro Provinciali ${ }^{2}$, Laura Mazzanti ${ }^{1}$ \\ ${ }^{1}$ Department of Experimental and Clinical Medicine, Università Politecnica delle Marche, Ancona, Italy \\ ${ }^{2}$ Department of Clinical Science, Biochemistry Section, Università Politecnica delle Marche, Ancona, Italy \\ Email: ${ }^{\dagger}$ nanetti@hotmail.com
}

Received 2 August 2013; revised 15 September 2013; accepted 1 October 2013

Copyright (C) 2013 Laura Nanetti et al. This is an open access article distributed under the Creative Commons Attribution License, which permits unrestricted use, distribution, and reproduction in any medium, provided the original work is properly cited.

\begin{abstract}
Homocysteine is a sulfhydryl-containing amino acid derived from the essential amino acid methionine. Total Hcy plasma level varies in the range of 5 - 15 $\mu \mathrm{mol} / \mathrm{L}$ in the normal population. Our aim in this study was to investigate the possible correlations among homocysteine plasma levels, oxidative stress parameters and clinical evolution of stroke. Fifty patients with large-vessel ischemic stroke were studied. Biochemical determinations were performed at entry (T0) and then repeated one month after stroke (T1). Homocysteine levels were significantly increased at $\mathrm{TO}$ with respect to $\mathrm{T} 1$ and showed a significant positive correlation with the expression of oxidative stress markers and a negative correlation with indicators of protective anti stress activity. A significant increase of antioxidant activity occurred from $\mathrm{T0}$ to $\mathrm{T} 1$ and changes were associated with the severity of clinical conditions. In particular, the extent of homocysteine and of oxidative stress markers plasmatic levels reduction and of the contemporary increase in anti stress biochemical activities were associated with a reduction of NIHSS scores. These findings, besides confirming an involvement of oxidative stress in influencing the evolution of stroke, suggest a role for homocysteine as a potentially modifiable biochemical alteration able to modulate some mechanisms involved in the production of ischemic damage.
\end{abstract}

Keywords: Homocysteine; Acute Stroke; Oxidative Stress; Platelets

\section{INTRODUCTION}

Homocysteine (Hcy) is a sulfhydryl-containing amino

${ }^{*}$ Conflict of interest: The authors declare that they have no conflict of interest.

${ }^{\#}$ These Authors equally contributed in this work.

${ }^{\dagger}$ Corresponding author. acid derived from the essential amino acid methionine, which is abundant in animal sources of protein [1]. Total Hcy (tHcy) plasma level varies in the range of $5-15$ $\mu \mathrm{mol} / \mathrm{L}$ in the normal population [2]. Minor genetic abnormalities or nutritional deficiencies of $\mathrm{B}$ vitamins, such as folic acid involved in methionine metabolism, can lead to increased tHcy concentration. The involvement of homocysteine in atherosclerosis was first promulgated by McCully on the basis of his pathological findings in infants with hyperhomocysteinemia resulting from inborn metabolism deficiency [3]. In experimental studies, homocysteine causes oxidative stress and vascular inflammation, damages endothelial cells, inhibits endothelium-dependent relaxation, and enhances thrombogenicity [4]. A large body of epidemiological studies suggest that increased homocysteine level may be considered as an independent risk factor for vascular diseases, including stroke [5-7].

Ischemic stroke is a heterogeneous syndrome caused by multiple disease mechanisms, resulting in a disruption of cerebral blood flow with subsequent tissue damage. The extent of focal cerebral injury is influenced by different molecular mechanisms. An alteration of the physiologic balance between production and degradation of enzymatic activity involved in the regulation of tissue oxidative status may play a role in influencing the results of the ischemic condition $[8,9]$. A recent study by our group proposed that cerebral ischemia causes the release of nitric oxide (NO) from the vascular endothelium. An elevated circulating concentration of the sulfur-containing amino acid homocysteine, hyperhomocysteinemia, produces complex changes within blood vessels. In the peripheral circulation, these changes include oxidative stress. Hyperhomocysteinemia-induced oxidative stress may occur as a result of decreased expression and/or activity of key antioxidant enzymes as well as increased enzymatic generation of superoxide anion (the precursor for multiple reactive oxygen and reactive nitrogen spe- 
cies).

The aim of this study was to analyze changes in homocysteine levels in ischemic stroke patients in the acute phase and after a month from disease onset. Furthermore, we investigated the possible correlations among homocysteine values, oxidative stress parameters and clinical evolution.

\section{PATIENTS AND METHODS}

Fifty patients with large-artery ischemic stroke [10] admitted to the Stroke Unit of the Neurological Clinic of the Marche Polytechnic University were enrolled. All subjects gave informed consent prior to the drawing of peripheral venous blood. The study was performed in accordance with the principles contained in the Declaration of Helsinki as revised in 2001, and the study was approved by the Bioethical Committee of the Marche Polytechnic University. The diagnosis of stroke was based on the presence of an acute-onset, persistent focal neurological deficit [11]. The diagnosis was then confirmed through CT scan within 24 hours from onset. Exclusion criteria were: previous stroke, evidence on CT of hemorrhagic cerebral lesion, neoplastic disease, chronic condition potentially able to influence oxidative status like severe cardiac, liver or renal failure, embolyzing cardiopathies and current treatment with statins. Patients with clinical or neuroradiologic evidence of lacunar infarction were also excluded in order to reduce the heterogeneity of our study population. In this respect, in a previous study, we demonstrated that changes in some oxidative stress markers are significantly lower in patients with lacunar stroke compared to large-vessel stroke patients [12]. Patients with dementia or other conditions hindering the possibility of obtaining consent to participate in the study were also excluded.

No included patient was observed within the timewindow suitable for fibrinolysis treatment.

Demographic characteristics, vascular risk profile and Oxfordshire Community Stroke Project classification of included patients are shown in Table 1. Metabolic parameters of patients at $\mathrm{T} 0$ and $\mathrm{T} 1$ are shown in Table 2.

Homocysteine levels of subjects with stroke were compared with 34 control subjects matched for age (18 men, 16 women $66 \pm 8$ Hcys $9.4 \pm 2 \mu \mathrm{mol} / \mathrm{L}$, fibrinogen $220 \pm 11)$. Biochemical determinations were performed at entry (T0) and then repeated one month after stroke (T1). Stroke severity on admission and at T1 was assessed with the National Institute of Health Stroke Scale (NIHSS) [12]. We used clinical parameters to characterize stroke severity, since the study design did not include a neuroradiological investigation performed with the appropriate time and modality to exactly measure the final extension of the ischemic lesion. For this reason CT data were only used to support the diagnosis of large
Table 1. Demographic data, risk factors and Oxfordshire Community Stroke Project (OCSP) classification of stroke patients.

\begin{tabular}{cc}
\hline No. of patients & $\mathbf{5 0}$ \\
Age, years & $68.2 \pm 9.6$ \\
Onset of Admission Interval, hours & $13 \pm 4.1$ \\
Male sex, \% & 58.0 \\
NHISS at admission, (mean \pm SD) & $10.08 \pm 1.35$ \\
NHISS at 1 month (mean \pm SD) & $3.33 \pm 0.25$ \\
Hypertension\% & 62.0 \\
Smoking, \% & 26.0 \\
Hypercholesterolemia, \% & 42.0 \\
OCSP classification & \\
${ }^{*}$ TACI \% & 10 \\
${ }^{* *}$ PACI \% & 90 \\
\hline
\end{tabular}

${ }^{*}$ Total anterior circulation infarct; ${ }^{* *}$ Partial anterior circulation infarct.

Table 2. Mean \pm SEM level of metabolic parameters in $\mathrm{T} 0$ and in $\mathrm{T} 1$.

\begin{tabular}{ccc}
\hline & T0 & T1 \\
\hline Total Cholesterol (mg/dl) & $181 \pm 40$ & $176 \pm 37$ \\
HDL (mg/dl) & $50 \pm 15$ & $46 \pm 11$ \\
LDL (mg/dl) & $111 \pm 30$ & $116 \pm 29$ \\
Triglycerides (mg/dl) & $105 \pm 40$ & $102 \pm 40$ \\
Fibrinogen (mg/dl) & $398 \pm 45$ & $387 \pm 40$ \\
Uric Acid (mg/dl) & $5.12 \pm 1.17$ & $5.30 \pm 0.93$ \\
\hline
\end{tabular}

artery stroke.

\section{PLATELET ISOLATION}

Peripheral venous blood was drawn after overnight fasting, and immediately mixed with Anticoagulant Citrate Dextrose (ACD) (36 ml citric acid, $5 \mathrm{mM} \mathrm{KCl}, 90 \mathrm{mM}$ $\mathrm{NaCl}, 5 \mathrm{mM}$ glucose, $10 \mathrm{mM}$ EDTA, $\mathrm{pH}$ 6.8). Platelets were isolated by differential centrifugation in anti-aggregation buffer (Tris-HCl $10 \mathrm{~mm}$; $\mathrm{NaCl} 150 \mathrm{~mm}$; EDTA $1 \mathrm{~mm}$; glucose $5 \mathrm{~mm}$; pH 7.4) according to Vignini et al. [13]. The method involved a preliminary centrifugation step $(200 \times \mathrm{g}$ for $10 \mathrm{~min})$ to obtain platelet-rich plasma (PRP). The platelets were then washed three times in anti-aggregation buffer and centrifuged as above in order to remove any residual erythrocytes. A final centrifugation at $2000 \times \mathrm{g}$ for $20 \mathrm{~min}$ was performed to isolate the platelets. The platelet pellet was washed twice in phosphate buffered saline PBS (containing $\mathrm{NaCl} 135 \mathrm{mM}$, $\mathrm{KCl} 5 \mathrm{mM}$, EDTA $10 \mathrm{mM}, \mathrm{Na}_{2} \mathrm{PO}_{4} 8 \mathrm{mM}, \mathrm{NaH}_{2} \mathrm{PO}_{4}$ $\mathrm{H}_{2} \mathrm{O} 2 \mathrm{mM}, \mathrm{pH}$ 7.2) and immediately used for the experiments or stored at $-80^{\circ} \mathrm{C}$.

Homocysteine levels were evaluated using a Microparticle Enzyme Immunoassay method with IMx (Abbott Diagnostic, Germany). Using this method, levels 
$<15 \mu \mathrm{mol} / \mathrm{L}$ were considered normal.

\section{NO PRODUCTION}

NO platelet production was evaluated by Assay Designs $^{\mathrm{TM}}$ Total Nitric Oxide Assay Kit (Catalog No. 917020; 192 Determination Kit); this commercial kit is complete for quantitative determination of total $\mathrm{NO}$ in biological fluids. The kit involves the enzymatic conversion of nitrate to nitrite, by the enzyme Nitrate Reductase, followed by the colorimetric detection of nitrite as a colored azo dye product of the Griess reaction [14] that absorbs visible light at $540 \mathrm{~nm}$. The modified protocol which employs deproteinization and reduction of nitrates to nitrites in the presence of NADPH-sensitive reductase, prior to addition of the Griess reagent, allows measurement of combined nitrite $\left(\mathrm{NO}_{2}^{-}\right)$, and nitrate $\left(\mathrm{NO}_{3}^{-}\right)$(recently named together as $\mathrm{NO}_{\mathrm{x}}$ ) and can be successfully applied for measurement of NO levels in human body fluids [15]. Since all products of NO and its derived species ultimately give only $\mathrm{NO}_{2}^{-}$and $\mathrm{NO}_{3}^{-}$, this modified Griess reaction allows a quantitative tally of all $\mathrm{NO}$ produced during a given period [16]. In this assay equal amounts of $1 \%$ sulphanylic acid and $0.1 \% \mathrm{~N}$-(1-naphthyl) ethylene diamine were added to the samples and the resulting absorbance was measured at $543 \mathrm{~nm}$. Blank (background) was determined in each experiment utilizing medium incubated without a sample. The amount of $\mathrm{NO}_{\mathrm{x}}$ in each sample was determined using a standard curve generated with known concentrations of $\mathrm{NO}_{\mathrm{x}}$ and expressed as $\mathrm{nmol}^{\mathrm{NO}_{\mathrm{x}}} / \mathrm{mg}$ protein. Protein concentration was determined by Bradford BioRad protein assay, using serum albumin as a standard to normalize the $\mathrm{NO}_{\mathrm{x}}$ concentration data [17].

This assay can be performed in a conventional spectrophotometer using 96-well microtiter plates, (provided with the kit) which require less sample volume and offer increased speed, throughput, and precision (due to simultaneous measurement of all standards and unknowns).

\section{PEROXYNITRITE PRODUCTION}

Peroxynitrite production in platelets was evaluated using the fluorescence probe 2,7-Dichlorofluorescein diacetate (DCFDA) as previously described [18]. DCFDA free base was prepared daily, by mixing $0.05 \mathrm{~mL}$ of 10 mmol/L DCFDA with $2 \mathrm{~mL}$ of $0.01 \mathrm{~N} \mathrm{NaOH}$, at room temperature for $30 \mathrm{~min}$. The mixture was neutralized with $18.0 \mathrm{~mL}$ of $25 \mathrm{mmol} / \mathrm{L}$ phosphate-buffered saline (PBS) $\mathrm{pH} 7.4$; this solution was maintained on ice in the dark until use [19].

Briefly, platelets were incubated for 15 min with 5 mM DCFDA-free base at $37^{\circ} \mathrm{C}$. Then the DCFDA treated platelets were divided into two sets: one set was incu- bated with the addition of a mixture of L-arginine 100 $\mathrm{mM}$ and NG-monomethyl-L-arginine (L-NMMA) 100 $\mathrm{mM}$ for $15 \mathrm{~min}$ at $37^{\circ} \mathrm{C}$ in the dark while the other set was incubated with the above mentioned mixture but only with PBS. After washing platelets twice in PBS (25 $\mathrm{mmol} / \mathrm{l}) \mathrm{pH} 7.4$, samples were sonicated to brake platelet pellets. The mixture was then centrifuged at $200 \times \mathrm{g}$ for $5 \mathrm{~min}$ and the fluorescence was measured in the supernatant in a Perkin-Elmer LS-50B spectrofluorometer, at an excitation wavelength of $475 \mathrm{~nm}$ and emission wavelength of $520 \mathrm{~nm}$. Blank samples contained all reagents except platelets. Fluorescence results obtained after LNMMA incubation were subtracted from those without L-NMMA. ONOO-production was corrected by protein concentration and was expressed in arbitrary fluorescence numbers/mg prot.

\section{TOTAL ANTIOXIDANT CAPACITY (TAC)}

Total antioxidant capacity was evaluated with a Biovision Assay kit. Biovision has developed a TAC Assay kit which can measure either the combination of both small molecule antioxidants and proteins or small molecules alone in the presence of Protein Mask. $\mathrm{Cu}^{2+}$ ion is converted to $\mathrm{Cu}^{+}$by both small molecules and proteins. The Protein Mask prevents $\mathrm{Cu}^{2+}$ reduction by proteins, enabling the analysis of only the small molecule antioxidant. The reduced $\mathrm{Cu}^{+}$ion is chelated with a colorimetric probe giving a broad absorbance peak of around $570 \mathrm{~nm}$, proportional to the total antioxidant capacity. Aliquots of frozen plasma were thawed at room temperature, and 10 $\mu \mathrm{L}$ of the samples were tested immediately. $10 \mu \mathrm{L}$ of Protein Mask was added in a plate. The reaction was started directly in the plate with $100 \mu \mathrm{L}$ of $\mathrm{Cu}^{2+}$ working solution. Plates were covered and incubated at room temperature for 1.5 hours. Trolox, a water-soluble tocopherol analog, was used as a reference standard. Standard curves were obtained by using increasing concentrations of Trolox in the same volume as for the sample. Absorbance was measured with a Hewlett-Packard 8450 A UV/ Visible spectrophotometer equipped with a cuvette stirring apparatus and a constant temperature cell holder. Unless stated differently, experiments were repeated 2 to 3 times. Qualitatively, similar results were obtained with individual values varying by less than $8 \%$.

In the lag mode, the assay mainly measures nonprotein and nonenzymatic antioxidants that are primarily extracellular chain-breaking ones, such as ascorbate, urate, and glutathione.

Plasma Lipid hydroperoxides were evaluated by measuring the levels of hydroperoxides using the ferrous oxidation xylenol orange assay (FOX-assay) in agreement with our previous studies [20]. Samples were incubated with FOX reagent $(100 \mathrm{mmol} / \mathrm{L}$ xylenol orange, 250 
$\mathrm{mmol} / \mathrm{L} \mathrm{Fe}^{2+}, 25 \mathrm{mM} \mathrm{H}_{2} \mathrm{SO}_{4}$, and $4 \mathrm{mmol} / \mathrm{L} \mathrm{BHT}$ in $90 \%$ methanol $(\mathrm{v} / \mathrm{v})$, then centrifuged at $4500 \mathrm{rpm}$ for $20 \mathrm{~min}$. The absorbance of the supernatant was determined at 560 $\mathrm{nm}$ and hydroperoxide levels were calculated using the molar coefficient $\left(4.3 \times 10^{4} \mathrm{M}^{-1} \mathrm{~cm}^{-1}\right)$ [20].

\section{SUSCEPTIBILITY TO OXIDATIVE STRESS IN VITRO}

The susceptibility to peroxidation was determined by measuring the production of thiobarbituric acid-reactive substances (TBARS) after incubation. Plasma was incubated at $37^{\circ} \mathrm{C}$ for $18 \mathrm{~h}$ with a freshly prepared $\mathrm{CuSO}_{4}$ solution added to the final concentration of $10 \mu \mathrm{M}$ to a solution containing $1 \mathrm{mg} / \mathrm{ml}$ of VLDL or HDL protein. Susceptibility to peroxidation was determined by measuring the production of thiobarbituric acid-reactive substances (TBARS) after incubation. The degree of lipoprotein oxidation was determined by measuring lipoperoxide level (TBARS) before and after peroxidative stress [21]. TBARS were determined using the Yagi et al. method [22]. Results are expressed as nanomoles malondialdehyde per $100 \mu \mathrm{g}$ protein. Proteins were measured by the Bradford method [17]. Oxidizability was determined as the difference in TBARS content before and after incubation with $\mathrm{CuSO}_{4}$.

\section{DETERMINATION OF CONJUGATED DIENES}

Conjugated dienes were assayed by monitoring the increase in absorbance at $234 \mathrm{~nm}$ as described previously [23].

\section{STATISTICAL ANALYSIS}

Statistical analysis was performed using the SAS statistical package (Statistical Analysis System Institute, Cary, $\mathrm{NC}$, USA). All results are expressed as mean $\pm \mathrm{SD}$. ANOVA was used to analyze the difference of results obtained in different experimental conditions. Differences were considered significant with $p<0.05$. Moreover, a linear correlation between Homocisteine and Fibrinogen, TAC and all oxidative stress parameters was used in order to observe a possible significant correlation. Differences were considered significant with $\mathrm{p}<0.05$.

\section{RESULTS}

Homocysteine values were significantly lower after one month (T1) from ischemic attack compared to stroke onset (T0) (Figure 1).

Moreover a significant positive correlation was found (Figure 2(a)) between Homocysteine and NIHSS score at T0 and T1 $(\mathrm{r}=0.849, \mathrm{p}<0.001 \mathrm{~T} 0$, and $\mathrm{r}=0.684 \mathrm{p}<$ $0.001 \mathrm{~T} 1)$ and between homocysteine and fibrinogen $(\mathrm{r}=$ $0.756, \mathrm{p}<0.001 \mathrm{~T} 0$, and $\mathrm{r}=0.747 \mathrm{p}<0.001 \mathrm{~T} 1)$ (Figure 2(b)), accompanied by a significant positive correlation between Homocysteine and peroxynitrite $(r=0.957$, $\mathrm{p}<0.001 \mathrm{~T} 0$, and $\mathrm{r}=0.915 \mathrm{p}<0.001 \mathrm{~T} 1)$ (Figure 3(a)), hydroperoxyde $(\mathrm{r}=0.846, \mathrm{p}<0.001 \mathrm{~T} 0$, and $\mathrm{r}=0.740 \mathrm{p}$ $<0.001 \mathrm{~T} 1)$, (Figure 3(b)), lipoperoxide $(\mathrm{r}=0.758, \mathrm{p}<$ $0.001 \mathrm{~T} 0$, and $\mathrm{r}=0.806 \mathrm{p}<0.001 \mathrm{~T} 1)$ (Figure 3(c)), and conjugates dienes $(\mathrm{r}=0.888, \mathrm{p}<0.001 \mathrm{~T} 0$, and $\mathrm{r}=$ $0.817 \mathrm{p}<0.001 \mathrm{~T} 1)$ (Figure 3(d)), at T0 and T1. On the other hand, a significant negative correlation between homocysteine and Nitric oxide $(\mathrm{r}=-0.965$ at $\mathrm{T} 0, \mathrm{p}<$

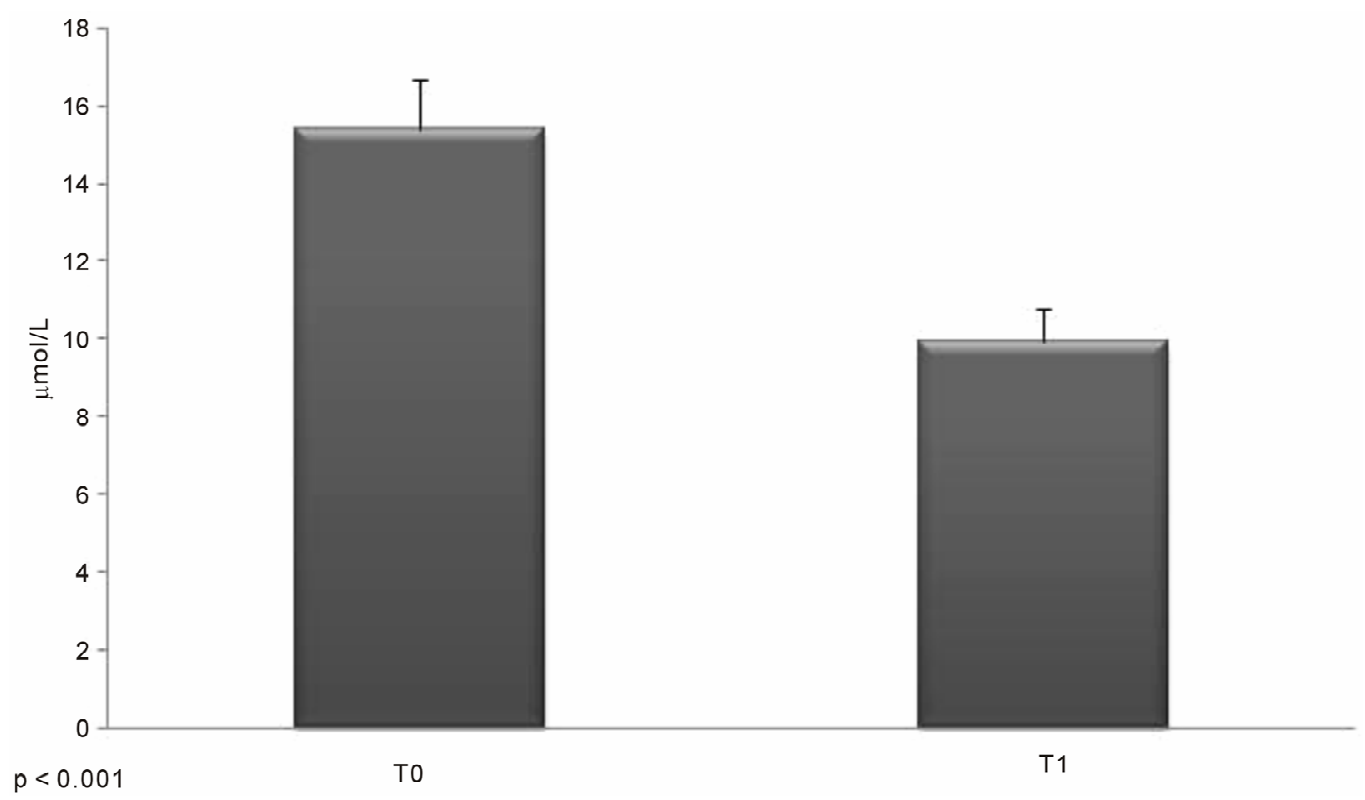

Figure 1. Homocisteine levels during an ischemic attack (T0) and after one month (T1). Results are expressed as means $\pm \mathrm{SD},(\mathrm{p}<0.001)$. 


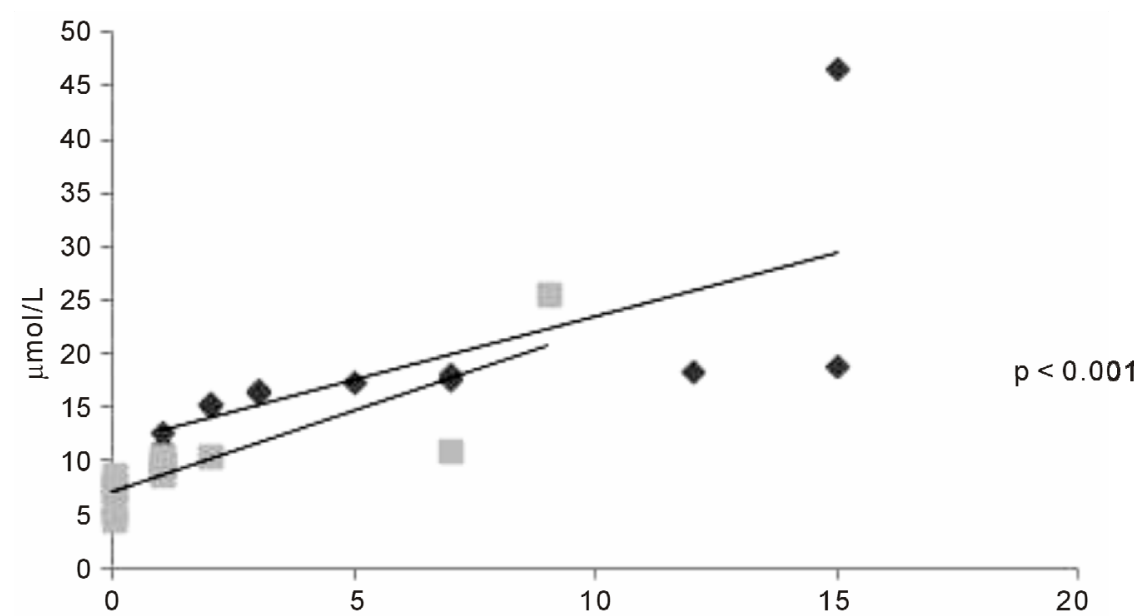

(a)

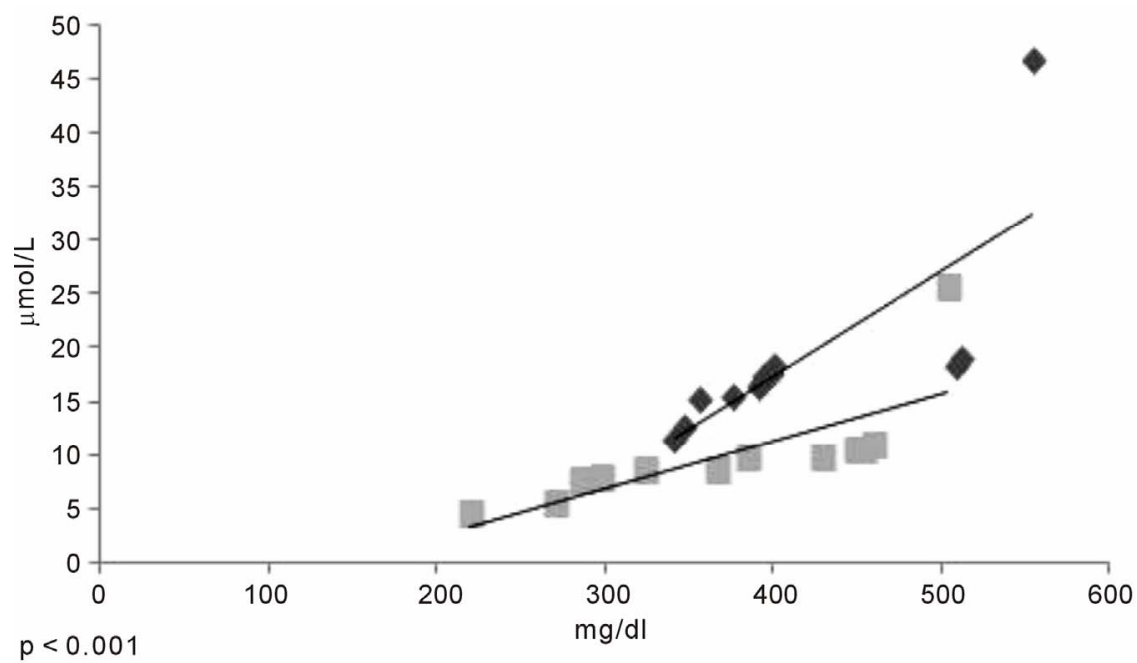

(b)

Figure 2. (a) Positive correlation between Homocysteine (TAC) and NIHSS score at T0

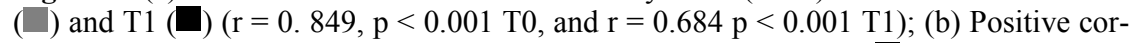

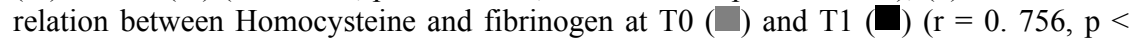
$0.001 \mathrm{~T} 0$, and $\mathrm{r}=0.747 \mathrm{p}<0.001 \mathrm{~T} 1)$.

0.001 and $\mathrm{r}=-0.920, \mathrm{p}<0.001$ at T1) (Figure 4(a)), and TAC $(\mathrm{r}=-0.782$ at $\mathrm{T} 0, \mathrm{p}<0.05$ and $\mathrm{r}=-0.949, \mathrm{p}<$ 0.001 at T1) at T0 and at T1 was observed (Figure 4(b)).

\section{DISCUSSION}

Idiopathic ischemic stroke is an important cause of death in general population and it is also emerging as a prominent health problem in developed countries [24]. Therefore, the correct identification of risk factors related to the development of cerebral ischemia could have important social health implications. Homocysteine is an endogenous amino acid, containing the free thiol group, which is involved in methionine and cysteine synthesis/resynthesis in healthy cells. Indirectly, Hcys participates in methyl, folate, and cellular thiols metabolism. Approximately $80 \%$ of total plasma Hcys is protein bound, and only a small amount exists as a free reduced Hcys (about $0.1 \mu \mathrm{M}$ ). The majority of the unbound portion of Hcys is oxidized to form dimers (homocystine) or combined with cysteine to form mixed disulphides [25, 26]. Elevated concentrations of homocysteine in human tissues, defined as hyperhomocysteinemia have been correlated with some pathological conditions, such as cardiovascular, neurodegenerative, and kidney disorders [27].

Hcys is an important endothelial aggression factor promoting endothelial dysfunction through different mechanisms, leading to atherosclerotic plaque formation. Hcy 1) inhibits the growth of endothelial cells, 2) induces an imbalance between $\mathrm{O} \bullet-$ and $\mathrm{NO} \bullet$ with deleterious effects on the vascular physiology, 3) induces the expression of different adhesion molecules, and 4) promotes the formation of modified LDL particles, which 


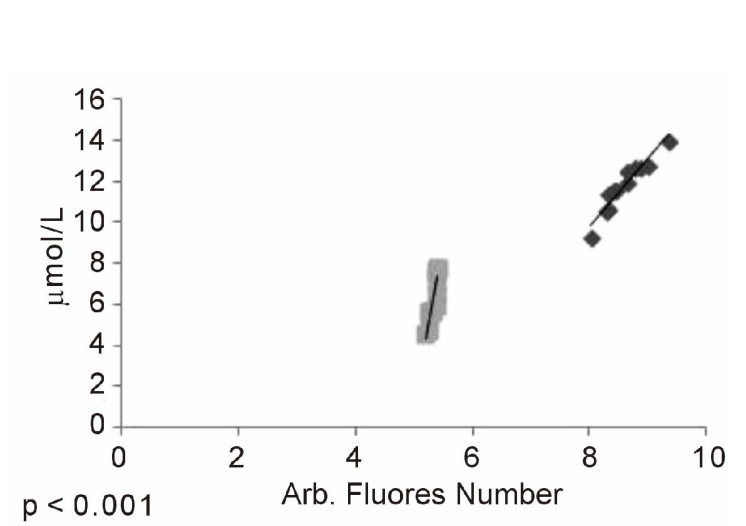

(a)

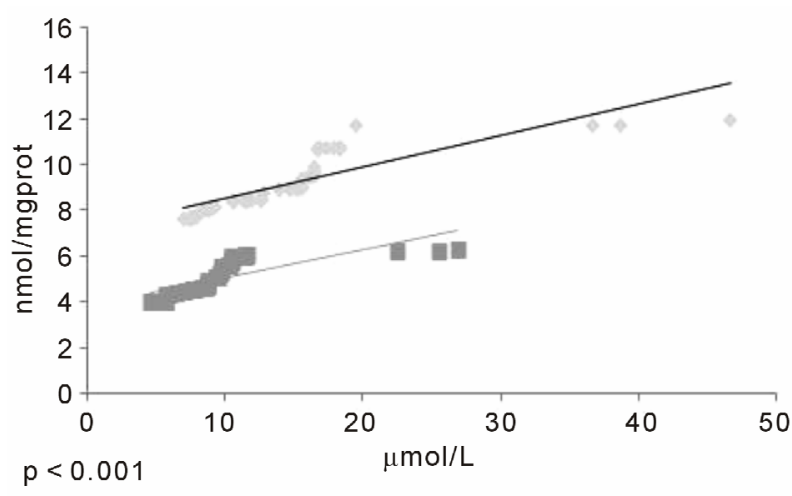

(c)

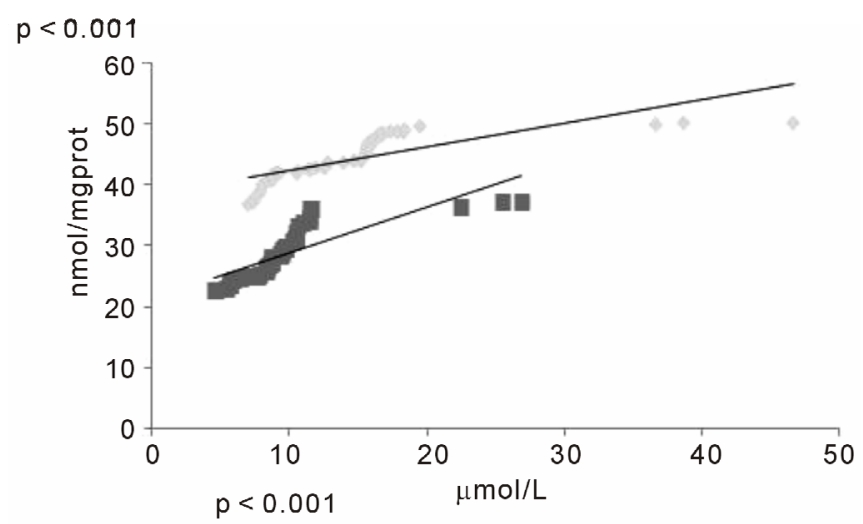

(b)

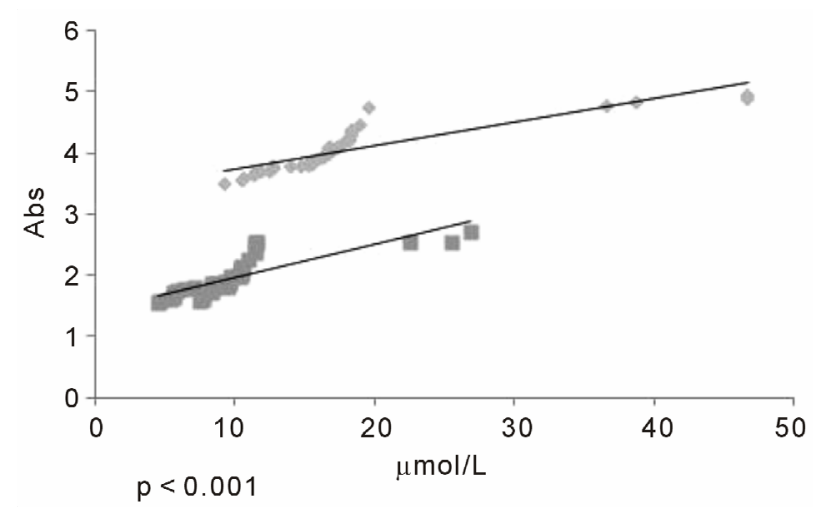

(d)

Figure 3. (a) Positive correlation between Homocysteine and peroxynitrite T0 ( $\square$ ) and $\mathrm{T} 1$ ( $\square)(\mathrm{r}=0.957, \mathrm{p}<$ $0.001 \mathrm{~T} 0$, and $\mathrm{r}=0.915 \mathrm{p}<0.001 \mathrm{~T} 1$ ); (b) Positive correlation between Homocysteine and hydroperoxyde at T0 ( $\square$ ) and T1 (ם) $(\mathrm{r}=0.846, \mathrm{p}<0.001 \mathrm{~T} 0$, and $\mathrm{r}=0.740 \mathrm{p}<0.001 \mathrm{~T} 1)$; (c) Positive correlation between Homocysteine and lipoperoxide at T0 $(\square)$ and T1 $(\square)(\mathrm{r}=0.758, \mathrm{p}<0.001 \mathrm{~T} 0$, and $\mathrm{r}=0.806 \mathrm{p}<0.001 \mathrm{~T} 1)$; (d) Positive correlation between Homocysteine and conjugates diene at T0 $(\square)$ and $\mathrm{T} 1(\square)(\mathrm{r}=0.888, \mathrm{p}<0.001 \mathrm{~T} 0$, and $\mathrm{r}=0.817 \mathrm{p}<$ $0.001 \mathrm{~T} 1)$.

are important players in the etiology of atherosclerotic plaque formation. These actions may justify the promoting action of increased plasmatic concentration of homocysteine on cerebrovascular diseases.

The present study provides some information about the mechanisms of oxidative stress in stroke and the role of Hcys.

In fact, our results suggest that elevated levels of Hcys at stroke onset may actively participate in the pathogenesis and evolution of ischemic damage (Figure 1) probably by an interference in mechanisms regulating oxidative stress.

The mechanism by which homocysteine promotes the production of hydroxyl radicals and lipid peroxidation initiators may be related to the reactivity of the sulfhydryl group leading to homocysteine autooxidation and thiolactone formation. Thus mild to moderate hyperhomocysteinaemia, even though not atherogenic per se, may lead to increased stroke severity as well as other classical risk factors [28].
In fact, in our study, Hcy levels increased stepwise with increasing NIHSS class, revealing a significant correlation between Hcy levels and NIHSS class severity of stroke both at onset and after 1 month.

Our finding of a parallel increase/decrease of Hcys and fibrinogen level at $\mathrm{T} 0$ and at $\mathrm{T} 1$ respectively, also suggested a possible role of Hcys in the modulation of the coagulation and fibrinolysis system. Other relevant findings were the significant positive correlation at $\mathrm{T} 0$ and $\mathrm{T} 1$ between Hcy levels and $\mathrm{ONOO}^{-}$, hydroperoxidation, lipoperoxidation, and conjugated diene. On the contrary, Hcy levels showed a significant negative correlation with NO levels and TAC.

Peroxynitrite (formed by the reaction of NO with superoxide) increases in peripheral blood vessels during hyperhomocysteinemia [4]. Peroxynitrite is known to activate poly (ADP-ribose) polymerase (PARP). Activation of PARP may be an important mediator of vascular dysfunction in other disease states such as diabetes. Homocysteine is also known to activate PARP, at least in 


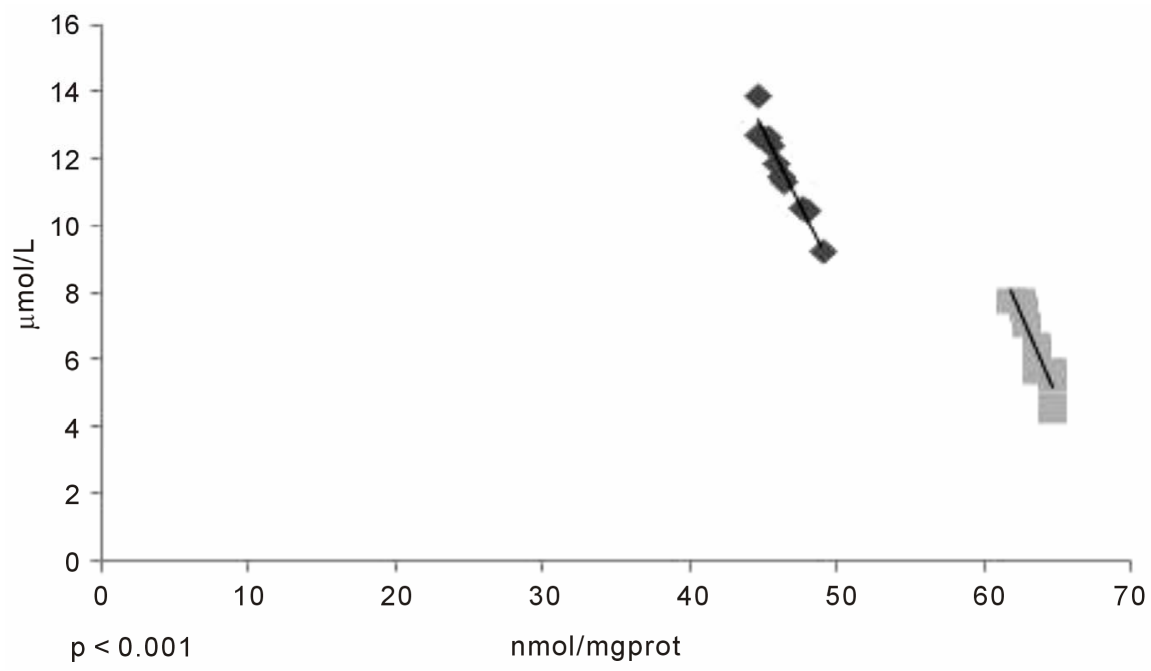

(a)

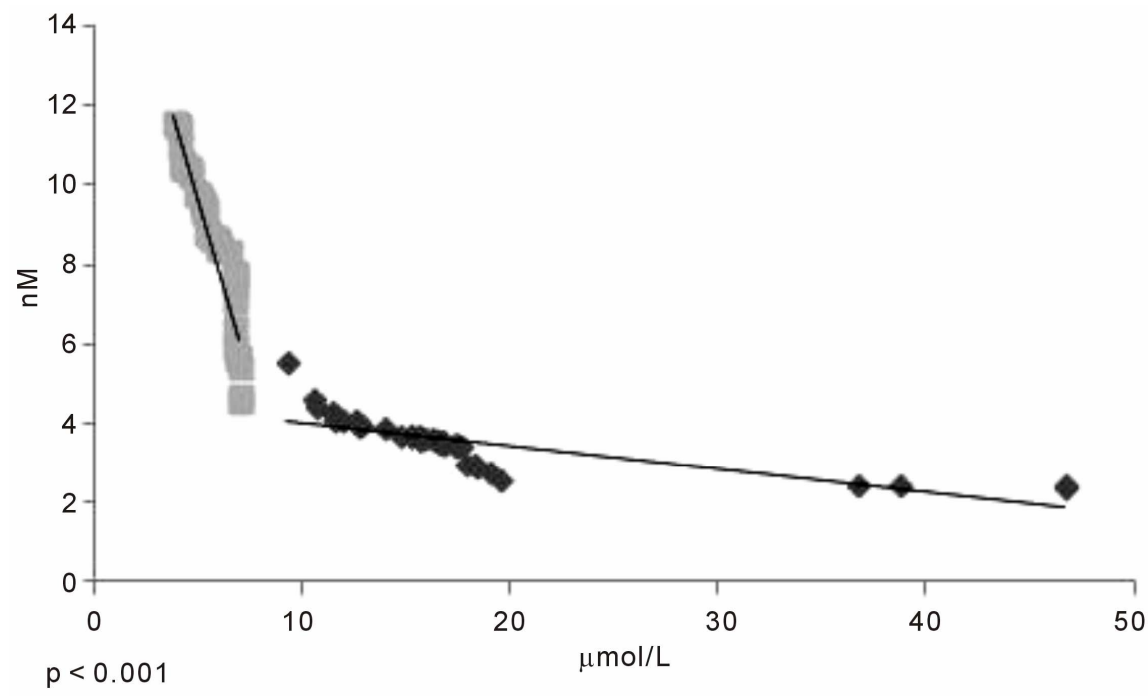

(b)

Figure 4. (a) Negative correlation between Homocysteine and NO at T0 ( $\square$ ) and T1 (ם) (r $=-0.965$ at T0, $\mathrm{p}<0.001$ and $\mathrm{r}=-0.920, \mathrm{p}<0.001$ at T1); (b) Negative correlation be-

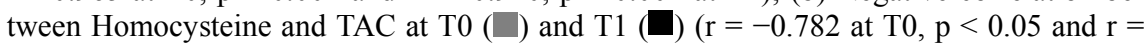
$-0.949, \mathrm{p}<0.001$ at $\mathrm{T} 1)$.

neurons, suggesting that PARP may potentially be involved in cerebral vascular dysfunction during hyperhomocysteinemia. Peroxynitrite can also produce vascular dysfunction and oxidative stress through nitration of protein tyrosine residues and promote the uncoupling of NO synthases, a circumstance in which the normal flow of electrons within NO synthase produces superoxide ions rather than NO [29].

In fact, a previous study suggested an involvement of oxidative stress mechanisms during the development of ischemic injury after stroke. The levels of lipoperoxyde, hydroperoxyde and diene conjugates resulted significantly higher at the time of the acute event than after a month [30].
This evolution seems to be influenced by the activation of endogenous compensatory mechanisms, as suggested by a significant increase of Total Antioxidant Capacity (TAC) from $\mathrm{T} 0$ to $\mathrm{T} 1$.

The significant correlation between oxidative stress markers levels and Hcy levels found in the present study suggests that Hcy levels control could positively interact with some of the pathological changes involved in the evolution of cerebral ischemic damage.

This concept seems to be reinforced by the negative correlation between HCY levels and NO and TAC at T0 and T1. In fact, this finding is in accordance with the hypothesis that increased homocysteine levels reduce defensive mechanisms against damaging effects of free 
radicals.

In conclusion, our data, obtained in a subgroup of patients with large-artery stroke, suggest an involvement of homocysteine in the pathogenesis of ischemic damage. In this respect, besides the possible use of hyper-Hcy as a prognostic marker, acute therapeutic interventions aimed at modulating Hcy levels should be considered as a further therapeutic strategy in patients with ischemic stroke, in the attempt to positively interfere with the biochemical mechanisms involved inoxidative stress.

\section{REFERENCES}

[1] Hankey, G.J. and Eikelboom, J.W. (1999) Homocysteine and vascular disease. Lancet, 354, 407-413. http://dx.doi.org/10.1016/S0140-6736(98)11058-9

[2] Durand, P., Prost, M., Loreau, N., Lussier-Cacan, S. and Blache, D. (2001) Impaired homocysteine metabolism and atherothrombotic disease. Laboratory Investigation, 81, 645-672. http://dx.doi.org/10.1038/labinvest.3780275

[3] McCully, K.S. (1969) Vascular pathology of homocysteinemia: Implications for the pathogenesis of arteriosclerosis. The American Journal of Pathology, 56, 111-128.

[4] Faraci, F.M. and Lentz, S.R. (2004) Hyperhomocysteinemia, oxidative stress, and cerebral vascular dysfunction. Stroke, 35, 345-347.

http://dx.doi.org/10.1161/01.STR.0000115161.10646.67

[5] Homocystein Studies Collaboration (2002) Homocysteine and risk of ischemic heart disease and stroke: A metaanalysis. JAMA, 288, 2015-2022.

http://dx.doi.org/10.1001/jama.288.16.2015

[6] Klerk, M., Verhoef, P., Clarke, R., Blom, H.J., Kok, F.J., Schouten, E.G., MTHFR Studies Collaboration Group (2002) MTHFR 677CT polymorphism and risk of coronary heart disease: A meta-analysis. JAMA, 288, 20232031. http://dx.doi.org/10.1001/jama.288.16.2023

[7] Towfighi, A., Markovic, D. and Ovbiagele, B. (2010) Pronounced association of elevated serum homocysteine with stroke insubgroups of individuals: A nationwide study. Journal of the Neurological Sciences, 298, 153-157. http://dx.doi.org/10.1016/j.jns.2010.07.013

[8] Nanetti, L., Giannubilo, S.R., Raffaelli, F., Curzi, C.M., Vignini, A., Moroni, C., Tanase, L., Carboni, E., Turi, A., Mazzanti, L. and Tranquilli, A.L. (2008) Nitric oxide and peroxynitrite platelet levels in women with small-forgestational-age fetuses. BJOG, 115, 14-21. http://dx.doi.org/10.1111/j.1471-0528.2007.01567.x

[9] Nanetti, L., Moroni, C., Vignini, A., Vannini, P., Franceschi, C. and Mazzanti, L. (2005) Age-related changes on platelet membrane: A study on elderly and centenarian monozygotic twins. Experimental Gerontology, 40, 519525.

[10] Adams, H.P., Kappelle, L.J., Biller, J., Gordon, D.L., Love, B.B. and Gomez, F. (1995) Ischemic stroke in young adults. Experience in 329 patients enrolled in the Iowa Registry of stroke in young adults. Archives of Neurology, 52, 491-495. http://dx.doi.org/10.1001/archneur.1995.00540290081021

[11] Aho, K., Harmsen, P. and Hatano, S. (1980) Cerebrovascular disease in the community: Results of a WHO collaborative study. Bulletin of the WHO, 58, 113-130.

[12] Taffi, R., Nanetti, L., Mazzanti, L., Bartolini, M., Vignini, A., Raffaelli, F., Provinciali, L. and Silvestrini, M. (2008) Plasma levels of nitric oxide and stroke outcome. Journal of Neurology, 255, 94-98. http://dx.doi.org/10.1007/s00415-007-0700-y

[13] Vignini, A., Nanetti, L., Raffaelli, F., Petrini, F., Tiano, L., Littarru, G.P. and Mazzanti, L. (2008) Effect of supplementation with fortified olive oil on biochemical markers of bone turnover in healthy women. Mediterranean Journal of Nutrition and Metabolism, 2, 117-120. http://dx.doi.org/10.1007/s12349-008-0015-2

[14] Sun, J., Zhang, X., Broderick, M. and Fein, H. (2003) Measurement of nitric oxide production in biological systems by using Griess reaction assay. Sensors, 3, 276284. http://dx.doi.org/10.3390/s30800276

[15] Guevara, I., Iwanejko, J., Dembińska-Kieć, A., Pankiewicz, J., Wanat, A. and Anna, P. (1998) Determination of nitrite/nitrate in human biological material by the simple Griess reaction. Clinica Chimica Acta, 274, 177-188. http://dx.doi.org/10.1016/S0009-8981(98)00060-6

[16] Moshage, H., Kok, B., Huizenga, J.R. and Jansen, P.L.M. (1995) Nitrite and nitrate determinations in plasma: A critical evaluation. Clinical Chemistry, 41, 892-896.

[17] Bradford, M. (1975) A rapid and sensitive method for the quantitation of microgram quantities of protein utilizing the principle of protein-dye binding. Analytical Biochemistry, 72, 248-254. http://dx.doi.org/10.1016/0003-2697(76)90527-3

[18] Vignini, A., Nanetti, L., Moroni, C., Tanase, L., Bartolini, M., Luzzi, S., Provinciali, L. and Mazzanti, L. (2007) Modifications of platelet from Alzheimer disease patients: A possible relation between membrane properties and NO metabolites. Neurobiology of Aging, 28, 987-994. http://dx.doi.org/10.1016/j.neurobiolaging.2006.05.010

[19] Nanetti, L., Taffi, R., Vignini, A., Moroni, C., Raffaelli, F., Bacchetti, T. and Mazzanti, L. (2007) Reactive oxygen species plasmatic levels in ischemic stroke. Molecular and Cellular Biochemistry, 303, 19-25. http://dx.doi.org/10.1007/s11010-007-9451-4

[20] Ferretti, G., Bacchetti, T., Moroni, C., Vignini, A., Nanetti, L. and Curatola, G. (2004) Effect of homocysteinylation of low density lipoproteins on lipid peroxidation of human endothelial cells. Journal of Cellular Biochemistry, 92, 351-360. http://dx.doi.org/10.1002/jcb.20069

[21] Rabini, R.A., Fumelli, P., Galassi, R., Dousset, N., Taus, M., Ferretti, G., Mazzanti, L., Curatola, G., Solera, M.L. and Valdiguié, P. (1994) Increased susceptibility to lipid oxidation of low-density lipoproteins and erythrocyte membranes from diabetic patients. Metabolism, 43, 1470-1474. http://dx.doi.org/10.1016/0026-0495(94)90003-5

[22] Yagi, K. (1994) Lipid peroxides and related radicals in clinical medicine. Advances in Experimental Medicine \& Biology, 366, 1-15.

http://dx.doi.org/10.1007/978-1-4615-1833-4_1 
[23] Esterbauer, H., Gebicki, J., Puhl, H. and Jürgens, G. (1992) The role of lipid peroxidation and antioxidants in oxidative modification of LDL. Free Radical Biology \& Medicine, 13, 341-349.

http://dx.doi.org/10.1016/0891-5849(92)90181-F

[24] Dragoni, F., Chiarotti, F., Rosano, G., Simioni, P., Tormene, D., Mazzucconi, M.G., Cafolla, A. and Avvisati, G. (2011) Thrombophilic screening in young patients $(<40$ years) with idiopathic ischemic stroke: A controlled study. Thrombosis Research, 127, 85-90. http://dx.doi.org/10.1016/j.thromres.2010.11.013

[25] Dietrich-Muszalska, A., Malinowska, J., Olas, B., Głowacki, R., Bald, E., Wachowicz, B. and Rabe-Jabłońska, J. (2012) The oxidative stress may be induced by the elevated homocysteine in schizophrenic patients. Neurochemical Research, 37, 1057-1062. http://dx.doi.org/10.1007/s11064-012-0707-3

[26] Ramakrishnan, S., Sulochana, K.N., Lakshm, S., Selvi, R. and Angayarkanni, K. (2006) Biochemistry of homocysteine in health and diseases. Indian Journal of Biochem- istry \& Biophysics, 43, 275-283.

[27] Manolescu, B.N., Oprea, E., Farcasanu, I.C., Berteanu, M. and Cercasov, C. (2010) Homocysteine and vitamin therapy in stroke prevention and treatment: A review. Acta Biochimica Polonica, 57, 467-477.

[28] Nanetti, L., Vignini, A., Raffaelli, F., Moroni, C., Silvestrini, M., Provinciali, L. and Mazzanti, L. (2008) Platelet membrane fluidity and $\mathrm{Na}^{+} / \mathrm{K}^{+}$ATPase activity in acute stroke. Brain Research, 1205, 21-26. http://dx.doi.org/10.1016/j.brainres.2008.02.005

[29] Faraci, F.M. (2003) Hyperhomocysteinemia: A million ways to lose control. Arteriosclerosis, Thrombosis, and Vascular Biology, 23, 371-373. http://dx.doi.org/10.1161/01.ATV.0000063607.56590.7F

[30] Nanetti, L., Raffaelli, F., Vignini, A., Perozzi, C., Silvestrini, M., Bartolini, M., Mazzanti, L. and Provinciali, L. (2011) Oxidative stress in ischaemic stroke. European Journal of Clinical Investigation, 41, 1318-1322. http://dx.doi.org/10.1111/j.1365-2362.2011.02546.x 